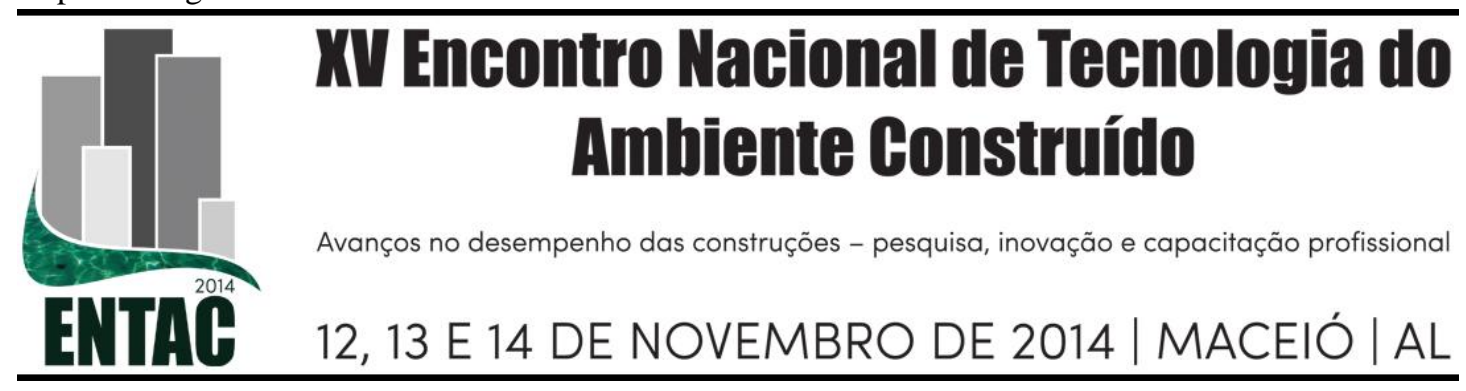

\title{
LÂMPADA DE GARRAFA PET: ALTERNATIVA PARA ILUMINAÇÃO NATURAL EM HABITAÇÃO DE INTERESSE SOCIAL DO SERTÃO ALAGOANO
}

CERQUEIRA, Rafaela (1); BARROS, Bruna (2);

(1) UFAL, rafaelao.carvalho@gmail.com (2) UFRGS, brunarb@gmail.com

\begin{abstract}
RESUMO
O Brasil vem passando por crises no espaço urbano, atingindo principalmente as camadas menos favorecidas da sociedade. Assim, faz-se necessário procurar formas de minimizar esses problemas de forma sustentável. Com base nisso, o presente trabalho apresenta uma experiência de extensão universitária, na qual se capacitou moradores de habitações de interesse social (HIS) do Alto Sertão de Alagoas na produção e uso de lâmpadas de garrafa PET para iluminação natural. Tal tecnologia visa reduzir custos, incorporar resíduos sólidos e melhorar o conforto lumínico de ambientes que não possuem janelas, o que é bastante corriqueiro em moradias populares.
\end{abstract}

Palavras-chave: Lâmpada de Garrafa PET, Habitação de Interesse Social, Extensão Universitária, Semiárido Alagoano.

\begin{abstract}
The Brazilian urban space has become troubled and it affects mainly the poor levels of the society. For this reason, it is necessary to find ways to minimize this problem with sustainable methods. Thus, this paper shows a participatory action research that enabled dwellers of social housing of the high backcountry of Alagoas to produce and use lamps made by PET bottles for daylighting. This technology intends to reduce costs, incorporate solid waste and improve the luminous comfort of rooms without windows. This situation is very common in social housing.
\end{abstract}

Keywords: PET bottle lamp, Social Housing, participatory action research, Semi-arid of Alagoas.

\section{INTRODUÇÃOO}

Para que o desenvolvimento aconteça de forma sustentável e igualitária, é necessário buscar alternativas para minimizar os problemas urbanos atuais. Entre esses problemas citam-se o acúmulo de resíduos sólidos, falta de moradias adequadas, falta de saneamento básico, entre outros.

Devido à necessidade de minimizar alguns destes problemas, apresenta-se neste trabalho uma experiência de extensão universitária, na qual se capacitou moradores de HIS do Alto Sertão de Alagoas na produção e uso de lâmpadas de garrafa PET para iluminação natural.

Esta lâmpada é uma forma inteligente de iluminar as casas sem gastar energia elétrica durante o dia. Ao se utilizar a lâmpada de garrafa PET, além de se obter melhorias nas habitações, as famílias podem economizar na conta de energia elétrica.

O presente trabalho é parte integrante do projeto de pesquisa-ação „Casa Lavoisier: Estudo e difusão de tecnologias não-convencionais com materiais recicláveis para HIS 
do Sertão alagoano ${ }^{\text {ee }}$ o qual foi realizado no ano de 2013 e integrou um programa de extensão voltado à formação socioambiental dos estudantes de engenharia e contribuições à população sertaneja (BARROS; AMORIM, 2011; BARROS et al, 2012). Deste modo, foram realizadas as etapas de levantamentos bibliográficos sobre o tema, seguida de confecção e teste de protótipos e, por fim, difusão das tecnologias sociais estudadas em oficinas de capacitação para moradores de HIS do local.

Assim, este trabalho se propõe a ampliar o debate sobre a importância de, não apenas estudar e desenvolver inovações tecnológicas de baixo custo para HIS, mas também difundi-las aos atores locais para sua adequada utilização. Igualmente, mostra que tais ações de intervenção podem ser feitas em locais distantes dos grandes centros, a exemplo do sertão nordestino, visto que estratégias como esta ainda são raras no País.

\section{METODOLOGIA}

O presente estudo se desenvolveu a partir de uma metodologia participativa, sendo classificada como uma Pesquisa-Ação. Essa metodologia estimula a participação das pessoas envolvidas na pesquisa e permite que se alcance um universo de respostas (MELO NETO, 2003). Desta forma, nota-se que há uma troca de conhecimentos entre escola/universidade e a população local, a qual é enriquecedora para ambos os atores.

Como procedimentos metodológicos, a pesquisa foi iniciada a partir da organização e tratamento de dados secundários sobre o tema e a realidade local. Foi realizada uma investigação teórica e análise crítica sobre o tema proposto, fundamentando uma visão mais geral sobre a problemática. Dentro desta revisão bibliográfica, pode-se destacar: dinâmica urbana e exclusão social; problemas socioambientais, sustentabilidade urbana; permacultura e princípios ecológicos; problemas habitacionais; resíduos sólidos; materiais e tecnologias construtivas não-convencionais; uso de materiais recicláveis como componentes da construção civil; dentre outros.

Dando continuidade, foi feita também uma catalogação de formas de utilização e de casos bem sucedidos de uso de resíduos recicláveis como componentes e tecnologias construtivas para habitações de interesse social (rurais e urbanas). A partir desta catalogação foi selecionada uma tecnologia, para confecção de protótipos, levando em conta os seguintes aspectos: baixo custo de produção, instalação, operação e manutenção da tecnologia nas habitações em comparação a tecnologias convencionais; desempenho da tecnologia, incluindo melhoria das condições de habitabilidade; facilidade de confecção, instalação, potencial de produção e reaplicação das tecnologias pelos próprios moradores e facilidade de obtenção do material reciclável.

Assim, optou-se pela confecção de protótipos de lâmpadas de garrafa PET, conforme justificativas apresentadas nos parágrafos anteriores. Após testes, realizou-se a difusão do conhecimento, com a promoção de uma oficina de capacitação. O público-alvo foi formado pelo grupo de mulheres do CRAS, pois estas são moradoras de áreas de interesse social de Delmiro Gouveia-AL. A oficina buscou ensinar, na prática, a confecção, aplicação e manutenção da referida tecnologia em habitações. $O$ foco foi mostrar que a tecnologia possibilita a melhoria das suas condições de habitabilidade, com custo reduzido e eficiência ambiental.

Por fim, para verificar o alcance das metas e impactos dessa atividade, foi aplicado um questionário para apreender as opiniões e percepções do público-alvo sobre a temática e sobre este projeto de pesquisa-ação. 


\section{PROBLEMAS HABITACIONAIS}

Nota-se que o processo de urbanização, que se intensificou no século XIX, fez com que grandes cidades começassem a nascer e, a partir disso, grandes aglomerações urbanas se formaram. No século XX, após duas guerras mundiais, iniciou-se um processo de inchaço e deterioração dos grandes centros urbanos. Com isso, gerou-se uma crise habitacional no Brasil (ACSELRAD, 1999).

Sabe-se que a desigualdade social é a principal causa da falta de moradias adequadas, pois, devido ao alto custo da terra urbana e a ausência de políticas públicas que viabilizem o acesso à terra para as classes menos favorecidas economicamente, essa camada da sociedade é obrigada a improvisar moradias em locais inadequados. Com isso, o governo brasileiro aponta um déficit habitacional de 6,490 milhões de unidades, o que corresponde a $12,1 \%$ dos domicílios do país, enquanto a inadequação atinge 13 milhões de domicílios urbanos, que corresponde a 26,4\% (FJP, 2010).

Dessa forma, afirma-se que muitos problemas socioambientais são causados, principalmente, devido aos problemas habitacionais como à falta de moradias ou inadequação. A erradicação da pobreza, assim como a resolução dos problemas habitacionais, são pontos-chave para o desenvolvimento sustentável nas cidades (SILVA; TRAVASSOS, 2008).

O déficit habitacional é medido por fatores como a falta de moradias, habitações precárias e a coabitação familiar, ou seja, quando várias famílias ocupam o mesmo imóvel. Diferente do déficit habitacional, a inadequação não necessita a construção de novas moradias, mas necessita de melhorias que proporcionem um padrão mínimo de habitabilidade. Assim, tem-se a carência de infraestrutura como ponto-chave da inadequação dos domicílios. São consideradas inadequadas as moradias que não dispõem de pelo menos um dos serviços básicos que seguem: iluminação elétrica, abastecimento de água, esgotamento sanitário e coleta de lixo (FJP, 2010).

Entretanto, no que diz respeito à inadequação, outros fatores deveriam ser considerados, como, por exemplo, a falta de aberturas para o exterior, visto que boa parte das casas das comunidades carentes possuem ambientes onde a única abertura é a porta. Isso prejudica o conforto ambiental e aumenta o consumo de energia elétrica. Uma solução para se obter iluminação natural nestas casas, e assim reduzir o consumo de energia elétrica, é a partir de iluminação zenital.

Dessa maneira, é necessário que se busque alternativas para minimizar os problemas habitacionais e uma alternativa para isso é usar materiais e tecnologias não convencionais com resíduos recicláveis para construção de moradias de interesse social (BARROS, 2008). Essas tecnologias implicam em um baixo custo para confecção e instalação, ao mesmo tempo em que beneficiam o meio ambiente, pois diminuem os resíduos que seriam descartados e demorariam centenas de anos para se decompor de forma natural. Além disso, proporcionam mais conforto às habitações já existentes, pois assim, é possível se conseguir melhor qualidade de vida para aqueles menos favorecidos economicamente.

\subsection{Resíduos Sólidos}

Os resíduos sólidos estão diretamente ligados a grande parte dos problemas socioambientais no mundo. Quando esses resíduos são depositados em locais inadequados, causam degradação ambiental como a poluição do ar, da água e do solo, gerando diversos outras problemas. 
As cidades utilizam cada vez mais materiais descartáveis e geram uma grande quantidade de resíduos sólidos. No mais, há intensa utilização dos recursos naturais, o que impede o crescimento sustentável das cidades, prejudicando o meio ambiente (LEAL; SOUZA, 2011).

A partir disso, para tentar minimizar os problemas causados pelos resíduos, existem leis e diretrizes que tornam a gestão dos mesmos mais eficientes e sustentáveis. Em 2010 foi sancionada a Lei Federal de $n^{\circ} 12.305 / 10$, que institui a Política Nacional de Resíduos Sólidos (PNRS), que prevê a prevenção e redução na geração de resíduos, a reciclagem e a reutilização dos resíduos sólidos, além de criar metas para eliminação dos lixões e impõe que os particulares elaborem seus Planos de Gerenciamento de Resíduos Sólidos. As ações voltadas para assegurar o cumprimento da PNRS ficam a cargo do poder público (BRASIL, 2010).

Uma das maiores preocupações da atualidade é o destino de materiais de difícil degradação, a exemplo do PET-poli (etileno tereftalato) ou poli (tereftalato de etileno). Por esse motivo, a reciclagem tem sido bastante incentivada para que o espaço de descarte seja diminuído e também devido ao seu alto valor econômico e seu potencial de reaproveitamento. Dados informam que apenas $15 \%$ dessas embalagens são recicladas, o restante é depositado no meio ambiente como em aterros, lixões, rios, terrenos abandonados, entre outros (ABIPET, 2003).

A reciclagem, juntamente com o reaproveitamento, tem se mostrado uma forma eficiente de conter o crescimento dos resíduos nas cidades. A garrafa PET pode ser facilmente reaproveitada, pois possui alta resistência à tração e uma durabilidade elevada, e por isso é ideal para ser usada como material alternativo na engenharia.

O PET deveria ser um dos plásticos mais fáceis de serem reciclados, porém existem várias limitações para a obtenção de produtos reciclados com alto valor agregado. Atualmente, o Brasil tem capacidade produtiva em torno de 360 mil toneladas anuais. Essa produção de embalagens, após usadas, geram grande impacto ambiental, devido a quantidade que é descartada todos os dias (GONÇALVES-DIAS; TEODÓSIO, 2006).

Assim, se houvesse coleta seletiva em todas as cidades, seria mais fácil conseguir mais PET com menos contaminação. A embalagem PET é totalmente reaproveitável, podendo ser reciclada várias vezes, sem perder sua qualidade. Quando é descartada num aterro sanitário, impermeabiliza as camadas em decomposição, prejudicando a circulação de gases e líquidos (GONÇALVES-DIAS; TEODÓSIO, 2006).

Como exposto anteriormente, a reciclagem do PET é muito importante para o meio ambiente. Outra opção para diminuir o descarte dessas embalagens é sua reutilização. Assim, neste trabalho será mostrada uma alternativa para reutilização da garrafa PET na construção civil, a lâmpada de garrafa PET.

\subsection{Materiais e Tecnologias Não-Convencionais com Resíduos Recicláveis Para HIS}

A indústria da construção civil é uma das que mais poluem e das que mais consomem grandes quantidades de recursos naturais. Além da degradação ambiental, o uso de materiais convencionais nem sempre é acessível à população de baixa renda. Assim, é necessário buscar alternativas para minimizar esses problemas. Com isso, vários estudos sobre o assunto estão sendo realizados para se tentar diminuir o uso dos recursos naturais, como por exemplo, aliando os materiais convencionais aos resíduos urbanos e industriais (CANELLAS, 2005). 
Existem inúmeros tipos de resíduos que podem ser incorporados na construção civil, e facilmente aplicados em construções de HIS. Pode-se citar como uma boa opção, a garrafa PET para ser utilizada na fabricação de painéis de parede e de cobertura, no enchimento de lajes, em blocos para execução de alvenarias de vedação com isolamento termo-acústico, e para iluminação natural de moradias (BARTH, 2004).

Entretanto, ainda existem muitas dificuldades na aplicação considerável desses materiais na construção civil, entre elas, pode-se citar: o preconceito, pois são denominados por várias pessoas de "material de pobre"; a bibliografia sobre o assunto é escassa, pois não há tantas pesquisas como sobre os materiais industrializados; não estão inseridos nos cursos convencionais de engenharia e arquitetura, com poucas exceções, de forma que os profissionais saem da universidade sem a menor visão sobre eles; faltam técnicos capacitados para aplicá-los; órgãos governamentais não conhecem ou ignoram tudo que não é convencional; falta de incentivos governamentais para resolver o problema habitacional dos países em desenvolvimento (BARBOSA, 2005).

Materiais e tecnologias não convencionais vêm se mostrando como uma ótima opção para diminuição da degradação ambiental. Quando estes incorporam resíduos urbanos, diminuem a quantidade de lixo que poluiria o meio ambiente. Além das vantagens ambientais, também permitem que pessoas de menor poder aquisitivo possam ter moradias dignas, pois esses materiais e tecnologias são de baixo custo e facilmente aplicáveis.

\section{LÂMPADA DE GARRAFA PET}

Sabe-se que no Brasil os altos custos de vida não permitem que todos tenham acesso à moradia digna e serviços básicos essenciais como: saneamento básico, coleta de lixo, energia elétrica. As classes de menor renda são as que mais sofrem com os problemas urbanos. Além dos problemas já citados, são também os mais atingidos com o acúmulo de resíduos sólidos decorrente do consumo exagerado de produtos descartáveis, que aumenta a cada ano.

Devido ao crescimento populacional e urbanização, o consumo mundial de energia deve aumentar, até 2020 , cerca de $60 \%$. O setor residencial é responsável por quase a metade do consumo de energia. Logo, faz-se necessária a substituição de formas convencionais de geração e uso da eletricidade por meios que diminuam o consumo de energia elétrica e que não agridam o meio ambiente (VENTTORAZZI et al, 2009). Desta forma, indicase a utilização de fontes de energia renováveis, como é o caso da energia solar.

Além disso, o consumo de energia elétrica pode ser diminuído com a adoção de estratégias passivas de condicionamento térmico e lumínico. Logo, as moradias devem ser projetadas, no mínimo, com todos os ambientes tendo aberturas para entrada de ventilação e iluminação natural.

Entretanto, é comum em HIS a existência de um número reduzido de janelas e, quando existem, são muito pequenas. No mais, é corriqueira a construção de ambientes como banheiros e despensas e, até mesmo, quartos, enclausurados, ou seja, sem a possibilidade de inserir janelas nas paredes. Assim, no que concerne ao aproveitamento da iluminação natural, uma alternativa é utilizar garrafas PET cheias de água no telhado, como mecanismo de iluminação zenital (LOUREIRO, 2003).

Essa tecnologia permite que as habitações tenham iluminação natural durante o dia, diminuindo assim o consumo de energia elétrica e, com isso, economizando na conta de energia. A luz emitida por essa lâmpada não-convencional é seguramente compatível 
com a luz emitida por uma lâmpada incandescente de 40 a 60 Watts (ibid). Essa tecnologia além de diminuir a conta de energia, não aquece o ambiente como a lâmpada incandescente e até ilumina mais e melhor.

Essa ideia foi do mecânico de Uberaba, Alfredo Moser que, em 2002, quando o Brasil corria risco de sofrer um apagão, percebeu uma oportunidade de reduzir sua dependência de energia elétrica durante o dia, fixando no telhado de casa garrafas plásticas cheias de água. Em seu projeto, ele utilizava uma garrafa PET de dois litros, contendo água limpa, à qual era adicionado o volume de duas tampas de água sanitária, sendo acoplado um recipiente plástico de filme fotográfico para proteger a tampa da garrafa PET da degradação proporcionada pelos raios do sol (XAVIER, 2008).

A ideia deu muito certo, e hoje já está presente em vários lugares do mundo, nas Filipinas, por exemplo, vem sendo difundido pela fundação MyShelter. Essas lâmpadas são usadas como opção para iluminação suplementar em casas e salas de aula da zona rural das Filipinas. Lá já existem cerca de 15.000 lâmpadas de garrafas solares em 20 cidades e províncias. Assim, a lâmpada de garrafa PET já atinge até as menores comunidades desse país, além disso, a tecnologia tem ajudado a gerar renda, pois, aqueles que possuem habilidades de carpintaria, instalam essas garrafas, cobrando um pequeno valor para isso. Essa tecnologia pode ser aplicada em qualquer local, pois os materiais são facilmente encontrados, mesmo nas áreas mais pobres. (A LITER OF LIGHT PROJECT, 2011).

Além dessas vantagens, essa tecnologia traz benefícios para o meio ambiente, pois provoca a diminuição da emissão de gás carbônico na atmosfera e possibilita reaproveitamento das garrafas PET que seriam descartadas, gerando poluição.

Ideias como essa precisam ser difundidas efetivamente, para que de fato cheguem até aqueles que precisam. Desta forma, realizou-se uma capacitação para moradores de HIS do Alto Sertão Alagoano para produção de lâmpadas de garrafa PET que visam melhorias na iluminação natural de residências.

Por fim, menciona-se que o ideal seria que medidas como essa se tornassem políticas públicas, visto que o aumento do consumo de energia elétrica pode acabar gerando uma crise no setor energético, principalmente nos períodos de longa estiagem, quando as hidrelétricas, que são a maior fonte de geração de energia do Brasil, estão com níveis baixos. Além disso, quando as hidrelétricas não são suficientes para fornecer toda a energia elétrica necessária nas cidades, são acionadas outras fontes de geração de energia, como as termoelétricas, que tem uma produção mais cara e mais poluente ou degradante, o que acarreta no aumento na tarifa de energia e prejuízos ambientais (PROCEL, 2004; PROAF, 2010).

\section{EXTENSÃO UNIVERSITÁRIA}

É preciso se pensar na construção de um mundo mais justo e melhor para todos, e a educação está diretamente ligada a isso. Nesse sentido, faz-se necessário pensar sobre a responsabilidade social universitária, uma vez que, sendo essa um local privilegiado de produção de conhecimentos e da formação de cidadãos, não pode se omitir de dar respostas à sociedade.

Entende-se por extensão toda atividade universitária que vise à integração universidadecomunidade. Com isso, trata-se de um processo interdisciplinar, educativo, cultural, científico e político que promove a interação transformadora entre Universidade e 
sociedade, sob o princípio da indissociabilidade entre ensino, pesquisa e extensão (FORPROEXT, 2012).

Várias concepções de extensão trazem consigo a perspectiva de que a universidade deve prestar um serviço à sociedade. A princípio, pensava-se que isso faria com que conhecimentos fossem passados para a sociedade, mas nenhum conhecimento a mais seria adquirido pelos universitários. Hoje essa compreensão mudou, onde se percebe uma troca de conhecimentos entre comunidade e universidade, enriquecendo também a formação dos graduandos envolvidos (MELO NETO, 2003).

De acordo com Pinto (2008), as universidades podem se considerar como instituições que formam recursos humanos socialmente responsáveis na medida em que conseguem articular os três elementos que compõem a tríade ensino, pesquisa e extensão. Estes elementos que fazem a universidade se dão em prol da produção de novos conhecimentos científicos e da ampliação e desenvolvimento de ações que beneficiem a sociedade, especialmente daquelas das proximidades da universidade, e de um ensino inovador e de qualidade.

\section{CAPACITAÇÃO PARA PRODUÇÃO E USO DE LÂMPADAS DE GARRAFA PET}

No intuito de disseminar conhecimento e oferecer melhor qualidade de vida para a comunidade local, foi realizada uma oficina de capacitação de construção de Lâmpadas de Garrafa PET. Essa oficina foi realizada no Centro de Referência de Assistência Social(CRAS) de Delmiro Gouveia, cidade do sertão alagoano, e contou com a presença de 24 mulheres associadas.

A oficina foi dividida em duas etapas. Na primeira, explanou-se sobre os aspectos gerais da lâmpada de garrafa PET, conceito histórico, funcionalidade e importância (Figura 1a). Na segunda etapa, os participantes confeccionaram as lâmpadas, com a orientação direta da equipe de pesquisadores (Figura 1b).

\section{Figura 1 - (a) Explicação sobre aspectos gerais; (b) Produção da lâmpada de garrafa PET}

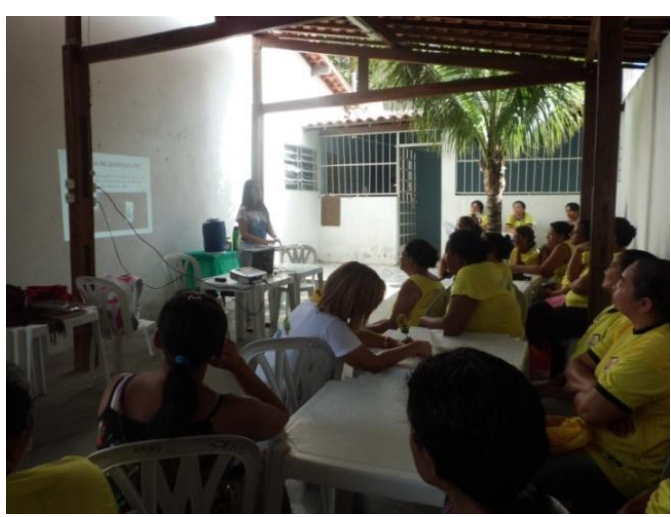

(a)

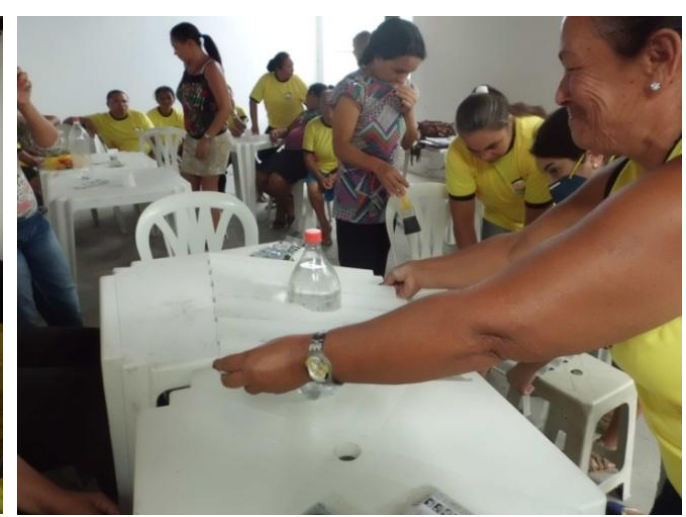

(b)

Fonte: Os autores (2013)

Para confecção da lâmpada de garrafa PET, as mulheres foram divididas em 3 grupos, e foi dado a elas os materiais necessários para cada grupo confeccionar uma lâmpada de garrafa PET. Os materiais e equipamentos usados para confecção da lâmpada foram: 
uma garrafa PET de 2 litros; dois litros de água limpa; uma medida de duas tampas de garrafa de água sanitária ou cloro; furadeira; e massa de vidraceiro ou cola epóxi.

Para a confecção, fez-se a marcação de uma circunferência com diâmetro igual ao da garrafa PET na telha, depois, com o auxílio da furadeira, executaram-se furos ao redor da marcação (Figura 2a). Preencheu-se a garrafa com água limpa e água sanitária. Por fim, encaixou-se a garrafa na telha e vedou-se com massa de vidraceiro (Figura $2 b$ ).

Figura 2 - (a) Recorte na telha; (b) vedação vertical com cola epóxi

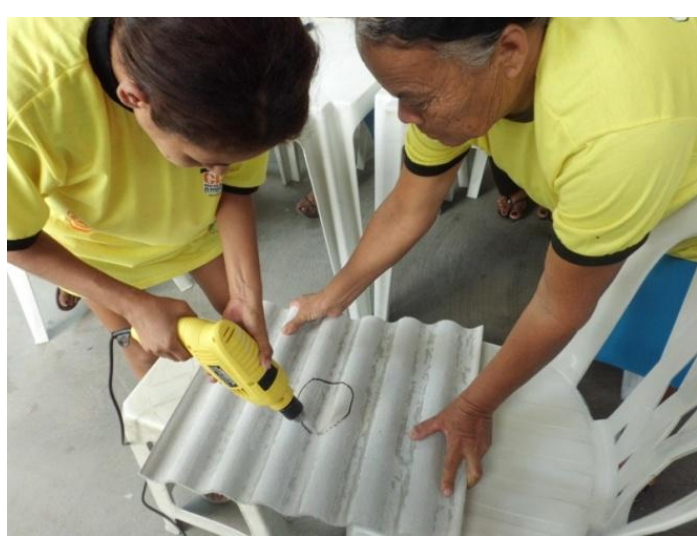

(a)



(b)

Fonte: Os autores (2013)

Para a avaliação de impacto da ação, questionários foram aplicados no público-alvo. Nestes, verificou-se que esta tecnologia teve uma boa aceitação e que os moradores pretendem instalar em suas residências. $\mathrm{O}$ questionário foi composto por 3 perguntas. São elas: O que você achou da oficina? $100 \%$ das mulheres responderam que foi boa ou ótima. Você gostaria de ter essa tecnologia em casa? 92\% responderam que sim. Você gostaria que voltássemos com novas oficinas de tecnologias não-convencionais? $100 \%$ responderam que sim.

\section{CONSIDERAÇÕES FINAIS}

O presente trabalho consistiu na apresentação de uma experiência de extensão universitária que capacitou moradores de uma comunidade do Alto Sertão Alagoano a produzir e utilizar lâmpadas de garrafa PET.

É de grande importância a criação de tecnologias alternativas, como a lâmpada de garrafa PET, para que o Brasil se desenvolva de forma sustentável e beneficie os mais necessitados. Mas só isso não basta, é necessário que essas ideias cheguem até aqueles que realmente precisam. A extensão universitária é uma forma de levar o conhecimento até a sociedade e precisa ser realizada mais efetivamente, pois grande parte da população não tem acesso ao conhecimento produzido dentro da Universidade.

No que se refere à lâmpada de garrafa PET, além de iluminar o equivalente a uma lâmpada incandescente de até $60 \mathrm{~W}$, dependendo da incidência solar, obteve uma ótima aceitação por parte das mulheres que participaram da oficina. Desta forma, políticas públicas deveriam ser realizadas para que ideias como essa cheguem as HIS, beneficiando os moradores, bem como as cidades, pois acarreta na diminuição do consumo de energia elétrica. 


\section{AGRADECIMENTOS}

A PROEST e ao Programa de Extensão AÇÔES pelo apoio.

\section{REFERÊNCIAS}

A LITER OF LIGHT PROJECT. Asia.Philippines, Manila \& Cebu, 2011.

ACSELRAD, H. Discursos da Sustentabilidade Urbana. Revista Brasileira de Estudos Regionais e Urbanos, Rio de Janeiro, v. 1, n.1, p. 79-90, 1999.

\section{ASSOCIAÇÃO BRASILEIRA DA INDÚSTRIA DO PET (ABIPET).9 CENSO DA RECICLAGEM DE PET, 2013.}

BARBOSA, N. P.. Considerações sobre materiais de construção convencionais e não convencionais. João Pessoa, 2005.

BARROS, B. R. Permacultura e Desenvolvimento Urbano: Diretrizes e Ações para a Sustentabilidade Socioambiental em Loteamentos de Interesse Social. Dissertação (Mestrado em Dinâmicas do Espaço Habitado) - Programa de Pós-Graduação em Arquitetura e Urbanismo, Universidade Federal de Alagoas, Maceió, 2008.

BARROS, B. R.; AMORIM, J. A.. A Extensão em Cursos de Engenharia: o Caso do Programa Ações do Campus do Sertão da UFAL. Anais do XXXIX Congresso Brasileiro de Educação em Engenharia - COBENGE, 2011, Anais...Blumenau, 2011.

BARROS, B. R.; AMORIM, J. A.; CANDEIAS, C. N. B. A Aprendizagem Baseada em Problemas em prol da Formação Socioambiental em Cursos de Engenharia: Relato de Experiência. Anais do $9^{\circ}$ ENEDS - Encontro Nacional de Engenharia e Desenvolvimento Social, 2012, Anais...Natal, 2012.

BARTH, F. et al. Reciclagem de garrafas PET para a pré-fabricação de Habitação de interesse social.Actas do Congresso Nacional da Construção - Construção 2004: Repensar a Construção. Editadas pela Secção de Construções Civis e FEUP Edições. Faculdade de Engenharia da Universidade do Porto, 13-15.

BRASIL. Lei $\mathrm{n}^{\mathrm{o}} 12.305$, de 2 de agosto de 2010. Institui a Política Nacional de Resíduos Sólidos; altera a Lei $\mathrm{n}^{\mathrm{0}}$ 9.605, de 12 de fevereiro de 1998; e dá outras providências.

CANELLAS, S. S.. Reciclagem de PET, visando à substituição de agregado miúdo em argamassa. Rio de Janeiro, 2005. 78f. Dissertação de Mestrado - Departamento de Ciência dos Materiais e Metalurgia, Pontifícia Universidade Católica do Rio de Janeiro.

FÓRUM DE PRÓ-REITORES DE EXTENSÃO DAS UNIVERSIDADES PÚBLICAS BRASILEIRAS(FORPROEXT). Política Nacional de Extensão Universitária. Manaus, 2012. 
FUNDAÇÃO JOÃO PINHEIRO/CENTRO DE ESTATÍSTICA E INFORMAÇÕES (FJP/CEI). Déficit habitacional municipal no Brasil. Belo Horizonte: Fundação João Pinheiro/Centro de Estatística e Informações, 2013.

GONÇALVES-DIAS, S. L.F. ; TEODÓSIO, A.S.S. Reciclagem do PET: desafios e possibilidades. In: ENEGEP - Encontro Nacional de Engenharia de Produção, 2006, Fortaleza. Anais...Rio de Janeiro: ABEPRO, 2006. v. 1.

LEAL, R. T. P.; SOUZA, C. E. G.Coleta Seletiva de resíduos Sólidos Urbanos Recicláveis com Catadores: um estudo sobre a viabilidade sócio-ambiental e econômica de sua implantação na cidade de São Gabriel/RS. 2011. Monografia. (Aperfeiçoamento/Especialização em Gestão Pública Controladoria) - Universidade da Região da Campanha, URC, Rio Grande do Sul, 2011.

LOUREIRO, P. S.. Reaproveitamento de Resíduos Sólidos Urbanos: a arquitetura transformando o resíduo em recurso. In: III Encontro Nacional sobre Edificações e Comunidades Sustentáveis, 2003. Anais...São Carlos, 2003.

MELO NETO, J. F.Extensão Universitária e Produção do Conhecimento. João Pessoa, 2003.

MENDES, I.A.C.; TREVIZAN, M.A.;CUNHA, A.M.P. CampusAvançado como Extensão Universitária. Rev. Bras. Enf, v.4, n.31, p.32-38, 1978.

PINTO, M. M. Responsabilidade social universitária como indicador de qualidade para o ensino superior? In: VIII Congresso Nacional de Educação - EDUCERE, 2008, Curitiba. Anais... Curitiba: Champagnat, 2008.

PONTIFÍCIA UNIVERSIDADE CATÓLICA DO RIO GRANDE DO SUL. Faculdade de Engenharia. Grupo de Eficiência Energética.USE - Uso Sustentável da Energia: guia de orientações / PUCRS, FENG, GEE, PU; coord. PROAF. Porto Alegre, 2010.

Programa Nacional de Conservação de Energia Elétrica(PROCEL). Gestão Energética Municipal. Rio de Janeiro, 2004.

SILVA, L. S.; TRAVASSOS, L. R. F. C.. Problemas ambientais urbanos: desafios para a elaboração de políticas públicas integradas. Cadernos Metrópole (PUCSP), v. 19, p. 27-47, 2008.

VETTORAZZI, E.; SANTOS, J. P.; STANGARLIN, H. Análise do emprego de garrafas PETs para o aproveitamento da luz natural em edificações da cidade de Santa Cruz do Sul - RS. In: ENCAC \ELACAC - X Encontro Nacional e VI Encontro Latino Americano de Conforto no Ambiente Construído, 2009, Natal - RN. Anais... Natal - RS: UFRN, 2009. v. 1.

XAVIER, G. D., et al. Caso Ampla: como reduzir furto e consumo de energia substituindo-se lâmpadas elétricas por garrafas pet. Rio's International Journal on Sciences of Industrial and Systems Engineering and Management, v. 2, p. Rm08401, 2008. 